\title{
Conflitos por águas e alocação negociada: o caso do vale dos Carás no Ceará*
}

\author{
Maria Inês Teixeira Pinheiro** \\ José Nilson B. Campos*** \\ Ticiana M. de Carvalho Studart****
}

SumÁrio: 1. Introdução; 2 . Contexto socioeconômico da área de estudo; 3. O aparato institucional; 4. O conflito de águas no vale dos Carás; 5. Conclusões.

Summary: 1 . Introduction; 2 . Socioeconomic context of the study area; 3 . The institutional apparatus; 4. Water conflicts in the Carás stream valley; 5 . Conclusions.

Palavras-chave: alocação de águas; conflitos por água; gestão de águas.

KEY WORDS: water allocation; water conflict; water resources management.

O artigo apresenta a descrição de um conflito de águas no estado do Ceará, envolvendo as águas perenizadas pelos reservatórios Thomas Osterne e Manoel Balbino, no vale do rio Carás, na bacia do rio Salgado, ao sul do estado. Ao longo dos anos, em períodos de pluviosidade normal, foram construídas pequenas barragens para captação das águas liberadas nos leitos dos riachos. Em épocas de escassez, o conflito instala-se no vale, em decorrência da retenção de águas a montante, que impedem

\footnotetext{
* Artigo recebido em fev. 2010 e aceito em jul. 2011.

** Doutoranda em recursos hídricos pela Universidade Federal do Ceará (UFC/DEHA). Professora efetiva do Eixo Tecnológico de Meio Ambiente do Instituto Federal de Educação, Ciência e Tecnologia do Ceará (IFCE/Maracanaú). Endereço: Av. Contorno Norte, 10, Parque Central Distrito Industrial — CEP 61925-315, Maracanaú, CE, Brasil. E-mails: inestp@ifce.edu.br e inestpinheiro56@gmail.com.

*** PhD em planejamento e gestão de recursos hídricos pela Universidade do estado do Colorado (CSU/USA). Professor titular do Departamento de Engenharia Hidráulica e Ambiental (DEHA) da UFC. Endereço: Campus do Pici, Centro de Tecnologia, bl. 713 - CEP 60455-900, Fortaleza, CE, Brasil. E-mail: jnbcampos@gmail.com.

**** Doutora em recursos hídricos pela UFC. Professora associada do Departamento de Engenharia Hidráulica e Ambiental (DEHA) da UFC. Endereço: Campus do Pici, Centro de Tecnologia, bl. 713 - CEP 60455-900, Fortaleza, CE, Brasil. E-mails: ticiana@ufc.br e ticianastudart2010@ gmail.com.
} 
o fluxo natural para os usuários a jusante. O artigo apresenta ainda a descrição do conflito e sua análise no contexto do modelo institucional do Ceará. É analisada também a prática da alocação negociada como estratégia de resolução de conflitos. Como resultado, conseguiu-se, pacificamente, a remoção de barragens de terra que interferiam no escoamento do trecho perenizado.

Water conflicts and negotiated allocation in Northern Brazil: the case of Carás valley in Ceará

The paper describes a water conflict for using the water regulated by the Thomas Osterne and Manoel reservoirs in Cara's river basin in southern part of Ceará State. Along the river, farmers have built small dams to withdraw waters released in the river from the reservoirs. In times of droughts, the conflict settled in due to the retention of water in upstream that prevented it came to users of downstream. The article also describes the Ceará State's institutional model and the way it deals with water conflicts. It is analyzed the practice of negotiating the water allocation as a strategy for conflict mediation. The main actors involved in conflict and its mediation were: users, technical water managers, prosecutors, political, and environmental institutions. As a result, it has been achieved, peacefully, the removal of earth's dams that interfered in the free flow of water.

\section{Introdução}

Nas últimas décadas, a água tem sido gradativamente reconhecida como recurso escasso em escala mundial, em função de suas limitações qualitativas, decorrentes da poluição, e de suas limitações quantitativas, derivadas, por sua vez, das adversidades climáticas, das demandas crescentes e de seu uso ineficiente.

O montante de água disponível em uma sociedade faz a diferença nas potencialidades de desenvolvimento. Dependendo do setor econômico priorizado - primário, secundário ou terciário - , a economia pode demandar mais ou menos água. Obviamente, o suprimento de água adequado pode viabilizar projetos agrícolas, o surgimento de polos industriais, assim como a movimentação de serviços que dependam de energia. Por outro lado, a insuficiência de água pode inviabilizar economicamente a região (Correia, 2006). O atraso no desenvolvimento da região Nordeste, em relação ao restante do Brasil, tem nas adversidades climáticas uma explicação. A água, por si só, porém, não é condição suficiente para o desenvolvimento, o que pode ser inferido da região Amazônica. Outros condicionantes podem existir.

Em decorrência do papel fundamental da água nas diversas atividades humanas, não é difícil prever que conflitos podem facilmente surgir em situações de escassez, tanto diante de uma demanda elevada, quanto da gestão 
inadequada. Conflitos oriundos da escassez de água têm sido cada vez mais frequentes por todo o planeta. Gleick (2000) relata 62 conflitos internacionais pelo uso da água nos últimos 500 anos, desde o conflito entre as cidades italianas Pisa e Florença, em 1503, até os conflitos no rio Ganges, na Índia, na década de 1990.

Diversos conflitos de água também ocorreram no Ceará durante o século XX e foram descritos por Pinheiro (2002), entre os quais se podem citar: 1. o dos rios Pacoti e Acarape, na década de 1920, com a construção de uma adutora para Fortaleza, retirando parte das águas que eram usadas por plantadores de cana-de-açúcar; 2. o do sistema Orós-Lima Campos, na década de 1990, em disputa pelas águas armazenadas no açude Orós e da derivação para os usuários do açude Lima Campos; e 3. o da transferência de águas da bacia do rio Jaguaribe para Fortaleza, na seca de 1993.

Os critérios para a análise de conflitos envolvem princípios éticos e devem estar inseridos na política de gerenciamento dos recursos hídricos, quanto aos objetivos, princípios e instrumentos da gestão. Na década de 1990, começaram as preocupações do Ceará sobre o gerenciamento das demandas de água dos usuários dos grandes e médios reservatórios do estado, fossem eles de montante, do entorno ou de jusante dos açudes. A técnica de alocação negociada entre usuários, moderada pela Companhia de Gestão dos Recursos Hídricos (Cogerh), é uma estratégia eficiente, aplicada como ferramenta de antecipação e gerenciamento de conflitos em secas.

\section{Contexto socioeconômico da área de estudo}

Para entendimento dos conflitos, suas causas e as ações de mediadores é importante fazer a contextualização do problema em suas bases física, hidrológica e socioeconômica. Descrevem-se nessa seção o meio físico, em seus aspectos hidrológicos e de regularização de águas, e ainda a ocupação do vale por irrigantes.

\subsection{0 meio físico}

O vale do riacho dos Carás situa-se na região do Cariri, ao sul do estado do Ceará, inserindo-se na região hidrográfica do rio Salgado. A bacia hidrográfica do Salgado abrange uma área de cerca de $13 \mathrm{mil} \mathrm{km}^{2}$ e nela habitam aproximadamente 850 mil pessoas, distribuídas em 23 municípios. A bacia, embora 
situada em solos sedimentares, não possui rios perenes; assim, foram construídos, ao longo dos últimos anos, cerca de 650 reservatórios, principalmente de pequeno porte. Já foram cadastrados mais de 1.700 poços (Cogerh, 2007). A região do conflito situa-se nos municípios de Crato e Juazeiro do Norte, que estão entre os cinco mais importantes do estado, em termos econômicos.

O riacho dos Carás, afluente da margem esquerda do rio Batateiras, foi perenizado com a construção de dois grandes reservatórios: o açude Thomas Osterne de Alencar, no município de Crato, e o açude Manoel Balbino, no município de Juazeiro do Norte. O Thomas Osterne barra as águas do riacho dos Carás nas proximidades de suas cabeceiras, e o Manoel Balbino barra o riacho dos Carneiros, afluente do riacho dos Carás, pela margem esquerda (figura 1).

Figura 1

Bacia do rio Salgado

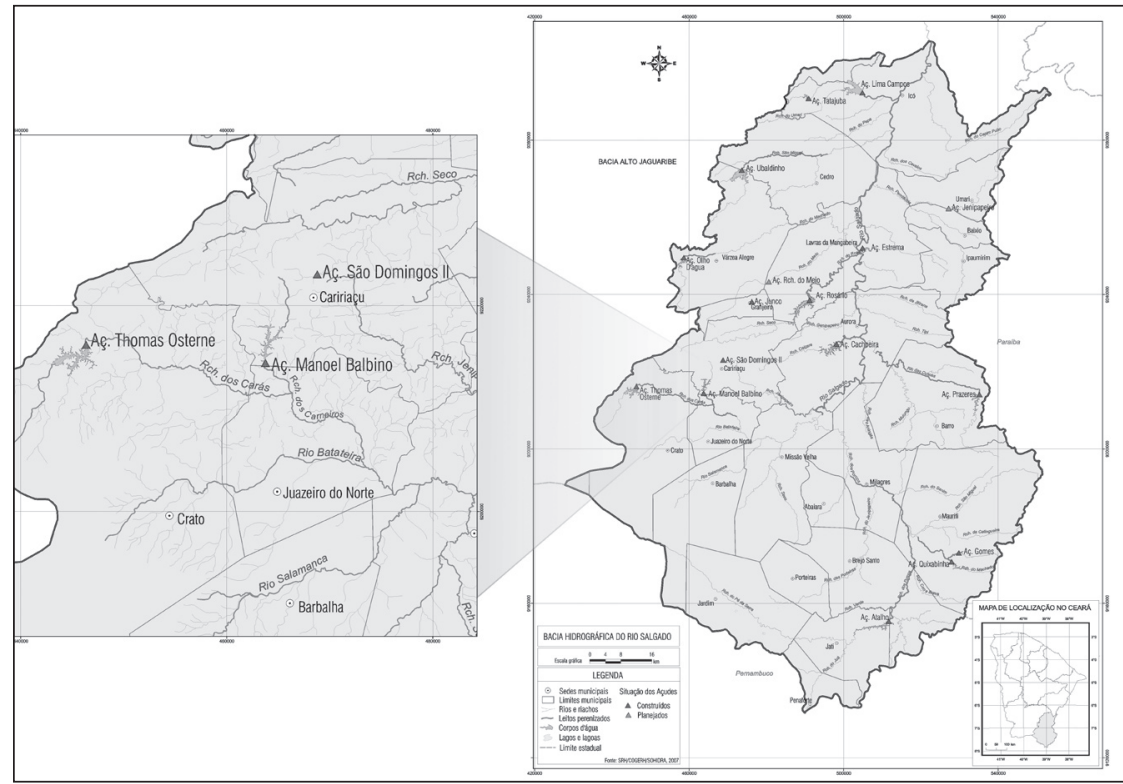

Fonte: Secretaria de Recursos Hídricos (SRH), 2007.

\subsection{A estrutura de uso das águas perenizadas}

A intermitência dos rios da bacia, como em todo o estado, com períodos secos em torno de nove meses (ou mais de um ano, quando da ocorrência de grandes secas), resultou em uma política de construção de pequenos, 
médios e grandes reservatórios sem uma visão sistêmica. Via de regra, os pequenos açudes são incapazes de promover uma regularização interanual e secam durante a ocorrência da estiagem. Nesses períodos, as disponibilidades se restringem aos estoques armazenados em grandes e médios reservatórios, quando surgem os conflitos pelo uso da água. Pode-se assinalar, portanto, que o uso das águas superficiais do estado, com ocorrência acentuada durante a estação seca, está intimamente associado à política de operação dos açudes.

No caso em estudo, os dois grandes reservatórios propiciaram a perenização do vale e, com ela, o estabelecimento de demandas ao longo do trecho perenizado. O reservatório Thomas Osterne foi construído no município de Crato, em 1982, com capacidade de acumulação de $28,78 \mathrm{hm}^{3}$, controlando uma bacia hidrográfica de $116,01 \mathrm{~km}^{2}$ e regularizando uma vazão de 0,57 $\mathrm{m}^{3} / \mathrm{s}$. Por sua vez, o reservatório Manoel Balbino foi construído em Juazeiro do Norte, em 1985, com capacidade de $37,18 \mathrm{hm}^{3}$, controlando uma bacia hidrográfica de $41,32 \mathrm{~km}^{2}$ e regularizando uma vazão de $0,08 \mathrm{~m}^{3} / \mathrm{s}$.

Observa-se que o reservatório Manoel Balbino tem maior capacidade de acumulação do que o açude Thomas Osterne, embora regularize um valor muito inferior. Segundo técnicos da região, o superdimensionamento do Manoel Balbino decorre da rivalidade histórica entre as cidades de Crato e Juazeiro do Norte, as maiores da região. Após a construção do Thomas Osterne, em Crato, houve intensa demanda política, em Juazeiro, pela construção de um reservatório maior.

A prática corrente do uso da água no vale dos Carás consiste na construção, pelos agricultores locais, de pequenos barramentos ao longo dos riachos para captar as águas perenizadas. Essa prática, apesar de ocasionar um pequeno aumento nas superfícies de evaporação, não é motivo de contenda entre usuários em anos normais, porque a vazão fornecida pelos dois açudes é suficiente para atender as demandas estabelecidas, as quais podem ser visualizadas no infográfico da figura 2. Podem-se observar cinco barragens de alvenaria, dez barragens de terra e quatro canais de derivação em um trecho de aproximadamente $45 \mathrm{~km}$, até a última barragem de terra.

Em anos de seca, entretanto, os conflitos se estabelecem, uma vez que a vazão liberada no leito dos riachos é reduzida e os usuários de montante retêm a água nos barramentos e a utilizam em função de suas necessidades, impactando os usuários de jusante, que reclamam seus direitos junto à Cogerh e aos promotores públicos. 
Figura 2

\section{Infográfico do vale do riacho dos Carás}

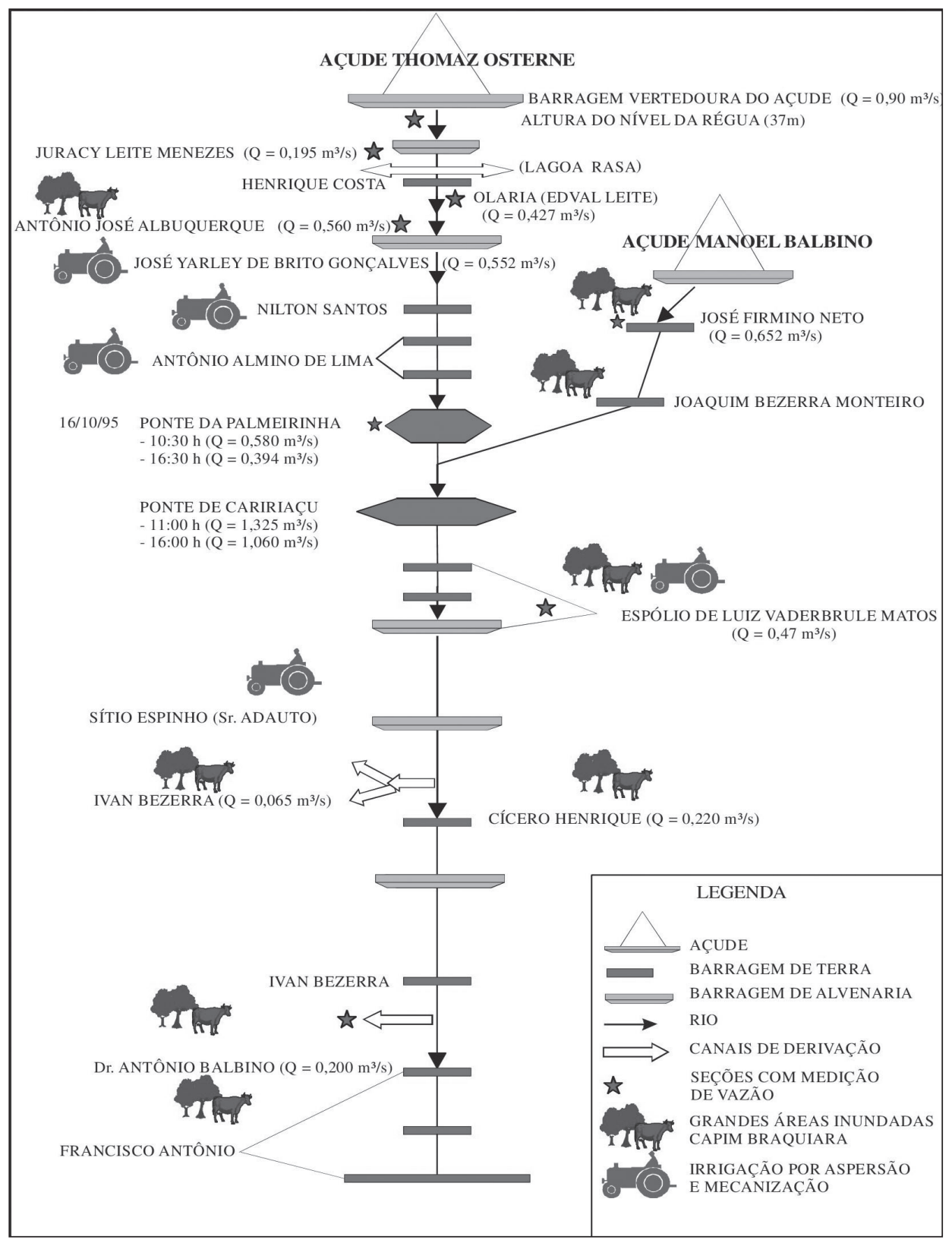

Fonte: Cogerh, 2000. 


\section{3. $\mathbf{O}$ aparato institucional}

Para gerenciar as águas e administrar os conflitos decorrentes da escassez, o estado do Ceará criou um aparato institucional que iniciou com a criação da Secretaria dos Recursos Hídricos, em 1987.

\subsection{0 processo de alocação: conceitos}

Segundo Campos e colaboradores (2002), a alocação de água engloba desde as atividades de avaliação das disponibilidades até aquelas de realocação, as quais somente têm lugar após o comprometimento de todos os recursos. A seguir, são apresentados alguns conceitos básicos do processo de alocação de águas.

- Alocação: representa o ato de distribuir determinado recurso entre usuários. Estes passam a ter direito de uso daquela quantidade que lhes foi alocada;

- Alocação inicial: compreende a primeira distribuição, entre os diversos usuários, da totalidade das disponibilidades hídricas conhecidas. Normalmente, acontece quando da organização do sistema institucional da gestão de recursos hídricos;

- Realocação: significa o ato de redistribuir determinado recurso, anteriormente alocado. A realocação procura redirecionar o uso do recurso escasso para novo objetivo para acompanhar a dinâmica da sociedade. O mercado de águas é um instrumento de realocação.

A realocação de recursos hídricos rapidamente aufere importância, notadamente nos últimos anos, pois, à medida que a população e as atividades econômicas se expandem, demandas maiores são geradas para um suprimento de água relativamente limitado (Campos e Studart, 2001).

Um recurso é alocado eficientemente quando é usado para maximizar seu valor. Pode-se prever, para a água, um grande número de usos diferentes e parcialmente concorrentes - agricultura, abastecimento humano, abastecimento industrial, turismo, lazer, piscicultura etc. Alcançar a eficiência significa, muitas vezes, a mudança do uso da água, ou realocação, intra ou intersetorial, como entre culturas de baixo e alto valor e da agricultura para a indústria, respectivamente (Kemper, 1996). 
Segundo Campos e Studart (2001), para que a água possa ser utilizada e controlada em níveis satisfatórios de quantidade e de qualidade, seja pela geração atual, seja pela futura, são necessários mecanismos de planejamento e gerenciamento integrado, descentralizado e, sobretudo, participativo.

Com a instituição da Política Estadual de Recursos Hídricos, em 1992, o usuário de águas passou a ser maior partícipe como decisor na gestão e no uso deste recurso natural. Anteriormente, a gestão era centralizada pelos órgãos federais e estaduais, enquanto o uso da água era praticado desordenadamente e de acordo com a conveniência do usuário.

\subsection{Instrumentos da gestão das águas}

Importantes avanços já aconteceram com a gestão participativa dos recursos hídricos e na alocação negociada das águas no Ceará, em especial na bacia no Curu, local onde se iniciou a aplicação dessa técnica. Desde a implementação da Política Estadual de Recursos Hídricos, houve significativos avanços no processo de definir a operação dos açudes. As definições da operação começaram a ser descentralizadas e com a participação da sociedade local. Nesse modelo, foram instituídos alguns instrumentos legais:

จ outorga: constitui o ato administrativo que assegura ao usuário o direito de usar água em determinado local, retirando-a de certa fonte hídrica, com uma vazão e um período determinado e para uma finalidade definida;

จ licença para obras hídricas: constitui o documento que autoriza a execução de qualquer obra ou serviço de oferta hídrica (açude, adutora, canal, poço etc.) que altere o regime, a quantidade ou a qualidade dos recursos hídricos;

จ cobrança pelo uso da água bruta: considerada um instrumento complementar da gestão, como forma de reduzir o desperdício e aumentar a eficiência no uso da água, e como fonte arrecadora de fundos para custear as despesas com o gerenciamento, a operação e a manutenção da infraestrutura hídrica.

\subsection{As unidades espaciais do gerenciamento}

No gerenciamento dos recursos hídricos, é conferido, ainda, importante destaque à organização dos usuários, como forma de garantir sua participação na 
gestão das águas. O apoio à organização dos usuários é desenvolvido, considerando-se três escalas espaciais:

v açude: núcleo básico de organização dos usuários, onde pescadores, vazanteiros, irrigantes e até mesmo concessionários de abastecimento de água dos centros urbanos dependem de um mesmo reservatório de água e devem, portanto, decidir conjuntamente sobre sua utilização. Neste nível, é apoiado o fortalecimento ou a constituição de associações;

v vale perenizado: este nível de organização é um pouco mais complexo, pois envolve um ou mais reservatórios e/ou trechos de rios perenizados, nos quais, ordinariamente, encontram-se os grandes perímetros públicos irrigados com irrigantes privados, agroindústrias, indústrias e captação para abastecimento de várias cidades, usuários que devem deliberar conjuntamente sobre a operação de um sistema perenizado;

v região hidrográfica: nível mais complexo dos três, já que abrange toda a área de uma região hidrográfica, a qual deve ser entendida como a unidade de planejamento e gestão, com todos os seus conflitos e potencialidades.

Uma vez consolidada a organização nos espaços "açude" e "vale perenizado", são constituídos os comitês de bacias, visando à concretização da gestão participativa dos recursos hídricos. O comitê de bacia, instituído por lei, é a instância mais importante de participação e de integração do planejamento e das ações na área dos recursos hídricos. O Decreto Estadual no 26.462, de 13 de dezembro de 2001, regulamenta e estabelece diretrizes para a formação e o funcionamento dos comitês de bacias hidrográficas (CBHs), órgãos que constituem o Sistema Integrado de Gestão dos Recursos Hídricos do estado.

Aos comitês são conferidos poderes deliberativos sobre a operação dos reservatórios e dos sistemas de vales perenizados; os critérios e normas para a outorga de uso dos recursos hídricos e de execução de obras ou serviços de oferta hídrica; estimular a proteção e a preservação dos recursos hídricos e do meio ambiente contra ações que possam comprometer o uso múltiplo atual e futuro; a implantação da tarifa sobre o uso da água bruta, assim como o destino dos recursos arrecadados com esta tarifa.

\subsection{A alocação negociada}

A alocação de água consiste no processo de definição de quantidades de água a serem alocadas em cada bacia e/ou trechos de rios para atender os consumos 
de água atuais e futuros. As questões quantitativas da água sempre foram de grande interesse da população e do estado. Nesse contexto, houve um avanço mais significativo no monitoramento quantitativo da água, sendo o sistema implantado fundamental para a gestão dos recursos hídricos. Na perspectiva de descentralização das ações nas bacias hidrográficas, a Cogerh instalou as unidades descentralizadas, denominadas "gerências de bacias".

Para o planejamento participativo e a alocação negociada de água das estruturas hídricas da bacia, a Cogerh, os CBHs e os conselhos gestores dos açudes utilizam a simulação de esvaziamento de reservatórios para diversas retiradas como apoio à tomada de decisão. São estabelecidos cenários de oferta de água de um reservatório ou de um sistema hídrico (mais de um açude) ao longo de determinado período, para atender às demandas dos diversos usos da água e trechos de rios perenizados. Mediante este recurso, a alocação de água é negociada nas reuniões de planejamento da operação dos reservatórios.

A metodologia adotada pela Cogerh para a operação de reservatórios e alocação da água goza de grande credibilidade junto aos técnicos do setor, usuários da água e comitês de bacia. A simulação de esvaziamento do reservatório consiste no balanço hídrico, no qual se têm como entradas a precipitação e os escoamentos superficiais, e como saídas a evaporação, o extravazamento e as retiradas, tanto pela tomada d'água, quanto diretamente na bacia hidráulica.

As decisões são tomadas nos seminários com o comitê, em escala de bacia hidrográfica, e com os conselhos gestores de açudes, em escala local. Para conduzir esse processo são necessárias informações precisas sobre a oferta e a demanda de água. Em síntese, a alocação negociada de água no Ceará tem as seguintes características:

1. ocorre anualmente após a quadra chuvosa;

2. são realizados seminários com as seguintes análises:

v situação atual dos reservatórios;

v simulação de esvaziamento dos açudes;

$\checkmark$ avaliação da demanda;

- definição da vazão a ser liberada;

v formação de uma comissão de usuários para acompanhamento;

3. registro em atas assinadas por seus participantes. 


\section{4. $\mathrm{O}$ conflito de águas no vale dos Carás}

O conflito no vale perenizado do riacho dos Carás sucede em razão da insuficiência de água em períodos secos para atendimento da demanda estabelecida ao longo dos anos considerados normais. Nesta seção, apresentam-se a evolução histórica do conflito, desde seu início em 1995 até o ano de 2007, uma descrição das decisões tomadas na reunião de alocação de 2007 e uma análise do conflito no contexto institucional descrito.

\subsection{A evolução do conflito}

O conflito inicia-se, formalmente, em meados da década de 1990, com a solicitação feita à Cogerh, pela Associação Comercial do Crato, para controle e utilização das águas do riacho dos Carás. Em 3 de outubro de 1995, o Ministério do Meio Ambiente, dos Recursos Hídricos e da Amazônica Legal solicitou à sua $2^{\mathrm{a}}$ Diretoria Regional da VII Região providências cabíveis para solucionar o problema. No dia 10 de outubro do mesmo ano, os usuários do trecho perenizado, sentindo-se prejudicados com os desvios das águas por meio de barramentos e canais, solicitaram ao Departamento Nacional de Obras Contra as Secas (DNOCS) providências para resolver o caso. Entre os dias 16 e 17 de outubro de 1995, a Cogerh realizou, juntamente com a Superintendência de Obras Hidráulicas do governo do estado do Ceará (Sohidra) e o Dnocs, levantamento de todos os barramentos e derivações que poderiam dificultar o uso racional da água no trecho de perenização do riacho dos Carás e do riacho dos Carneiros. Logo após o estudo, houve reunião envolvendo todos os usuários do vale, tendo sido acordado o janelamento (abertura regular) das barragens de alvenaria que prejudicariam os usuários de jusante.

Em 1997, a SRH/CE, na tentativa de estabelecer o equilíbrio entre os grandes e os pequenos usuários de água, contratou uma empresa para demolir as barragens de terra e executar o janelamento nas barragens de alvenaria de pedras, a fim de permitir o escoamento da água para jusante e reduzir a superfície de evaporação. Esperava-se, na ocasião, que os reservatórios Thomas Osterne e Manoel Balbino pudessem operar com vazões 300 l/s e 50 l/s, respectivamente, compatíveis com as águas armazenadas.

Em agosto de 1998, ano de seca, os proprietários situados às margens do riacho dos Carás, em Juazeiro do Norte e Missão Velha, em dificuldades com a falta d'água no riacho, mobilizaram-se com o apoio do vereador de Juazeiro do Norte, José Eraldo Oliveira Costa, em busca de soluções. A Câmara 
Municipal de Juazeiro do Norte, com base nas denúncias sobre a existência de barramentos irregulares em algumas propriedades ao longo do riacho dos Carneiros, solicitou à Cogerh vistoria técnica sobre o problema. A mesma solicitação foi feita pelo Decom do município.

As constatações da Cogerh, descritas no relatório de Inspeção Operacional, foram enviadas à Câmara Municipal de Juazeiro do Norte e ao Decom. A vistoria constatou que alguns proprietários das barragens passaram a fechar as comportas, provocando desperdícios com a derivação de água para inundação de grandes áreas de capim.

Durante o mês de novembro de 1999, atendendo à requisição da juíza da $5^{\text {a }}$ Vara da Comarca de Juazeiro do Norte, a Cogerh realizou outra inspeção técnica para averiguar possíveis irregularidades nos trechos perenizados do riacho dos Carneiros, para instruir a ação judicial em trâmite no fórum de Juazeiro do Norte.

O Conselho de Representantes dos dois açudes promoveu reuniões em agosto e setembro de 2000 para discutir medidas a fim de sanar o referido problema, produzindo um documento que foi enviado à Procuradoria da República no estado do Ceará. Durante esse período, a Cogerh demoliu algumas barragens de terra, após negociação com os proprietários. Inicialmente, dois deles foram resistentes à desobstrução do riacho, mas cederam a posteriori.

Em novembro de 2000, a Cogerh solicitou apoio da Empresa de Assistência Técnica e Extensão Rural do Ceará (Ematerce) para realizar nova vistoria ao longo do vale perenizado do riacho dos Carás, com a presença de representantes do Sindicato dos Trabalhadores Rurais de Juazeiro do Norte e da comissão de usuários dos açudes em foco. Durante a visita técnica, a Cogerh realizou medições de vazão em vários pontos estratégicos do riacho, para as perdas no escoamento serem quantificadas. Conforme parecer da Ematerce, durante a fiscalização, os barramentos encontravam-se com suas aberturas livres, permitindo o escoamento normal da água. Um barramento que represava uma quantidade considerável de água teve suas comportas abertas no dia da visita.

A Procuradoria da República no estado do Ceará solicitou à Cogerh, em fevereiro de 2001, informações sobre os fatos descritos pelo Conselho de Representantes da bacia do rio Salgado e pela comissão de usuários dos açudes Thomas Osterne e Manoel Balbino, enviadas à procuradoria em 27 de setembro de 2000. Tratava-se de um pedido de providências sobre o uso irregular das águas no vale do riacho dos Carás, conforme processo SPU-Sead/CE $\mathrm{n}^{\mathrm{o}}$ 01.055.233-2. A Cogerh, mais uma vez, descreveu todo o histórico da situação do conflito, informando, na oportunidade, que os órgãos envolvidos na negociação conheciam a complexidade do problema, e consideravam necessária 
uma ação conjunta de setores diversos para chegar-se a resultado positivo no uso da água. Ressaltava, ainda, que seria fundamental o constante compromisso, não só dos órgãos públicos, mas, sobretudo, dos próprios usuários dos vales, na fiscalização das ações maléficas para a perenização dos vales, denunciando os fatos e cobrando a ação pública. A companhia encaminhou ao Ministério Público Federal (MPF) as informações sobre o conflito, na expectativa de que o órgão solucionasse aquelas questões que fugiam do alcance técnico.

Em maio de 2002, a SRH/CE informou que o MPF ainda não tinha proposto nenhuma solução, dando conta, também, de que os usuários dos vales perenizados não possuíam a outorga. Alertou igualmente para o fato de que isso dificultaria o dimensionamento das áreas reais de irrigação.

Durante os anos de 2003 e 2004, a Cogerh, em reuniões de operação dos açudes Thomas Osterne e Manoel Balbino, debateu sobre como usar as águas dos açudes para obter ganhos econômicos e reforçou a necessidade de participação dos usuários, estabelecendo-se a prática de não reservar as águas liberadas no leito do riacho.

Segundo informações da Cogerh, em janeiro de 2005, após a reunião de operação dos açudes, ocorrida em 12 de agosto de 2004, na cidade de Crato, a comissão de usuários dos açudes Thomas Osterne e Manoel Balbino solicitou à Cogerh, em 16 de setembro de 2004, providências quanto à abertura dos barramentos ao longo do vale, mais especificamente nas propriedades dos senhores Ivan Bezerra, Balbino e Francisco Antônio. Mais uma vez, os técnicos da Cogerh foram à área e detectaram a existência de barramentos, dificultando o escoamento natural do curso d'água, e que os referidos proprietários não possuíam licença para construção de obras hídricas nem o licenciamento ambiental e a outorga, previstos em lei. A Cogerh solicitou a participação do Instituto Brasileiro de Recursos Naturais Renováveis (Ibama), com o intuito de amenizar ou solucionar o litígio.

Como o leito do riacho é muito assoreado, o que favorece o extravasamento e a inundação, a Cogerh começou em 2005 a limpeza no leito do riacho com o intuito de melhorar o escoamento da água e amenizar o problema. Em junho de 2007, foram desobstruídos cerca de $4 \mathrm{~km}$ do riacho dos Carás (Cogerh, 2007).

\subsection{A alocação negociada no ano de 2007}

A alocação negociada de água na bacia do rio Salgado iniciou-se em 2000. Naquele ano, a Cogerh designou um gerente para atuar na bacia do Salga- 
do, dando mais agilidade às ações de gerenciamento dos recursos hídricos. Foram criados o Comitê da Bacia e a Comissão de Açudes. Com o objetivo de mostrar a dinâmica das participações no Comitê de Bacia e na Comissão de Açudes, apresenta-se, a seguir, o delineamento da alocação negociada no ano de 2007.

No período compreendido entre 2000 e 2006, as alocações negociadas ocorriam somente no âmbito do Comitê da Bacia. No ano de 2007, foi adotada nova estratégia: a negociação passou a acontecer, em primeira instância, no Comitê da Bacia e precisava ser referendada ou modificada na Comissão de Açudes. O Comitê da Bacia, em primeiro de junho, deliberou que a vazão liberada no reservatório Manoel Balbino seria entre 45 l/s e 65 l/s e para o açude Thomas Osterne seria entre $250 \mathrm{l} / \mathrm{s}$ e $300 \mathrm{l} / \mathrm{s}$.

No dia 14 de junho do mesmo ano, com a presença de técnicos da Cogerh, usuários dos açudes, convidados e o secretário-geral do comitê da bacia hidrográfica do rio Salgado, foi realizada a reunião no âmbito da Comissão de Açudes.

A reunião iniciou com a apresentação, por técnicos da Cogerh, dos dados históricos das cotas da água nos reservatórios e avaliação de vários cenários de oferta de água. Foram mostrados quadros e figuras referentes à evolução do volume armazenado, operação planejada versus realizada e simulação de esvaziamento no ano anterior. Essa apresentação teve como objetivo mostrar aos usuários a qualidade do modelo de simulação. Comentou-se sobre o superdimensionamento do açude Manoel Balbino, cujo volume máximo atingido foi de 37 milhões de $\mathrm{m}^{3}$, equivalentes a $55 \%$ de sua capacidade.

Durante a reunião, foram discutidos vários assuntos com a participação dos presentes. Um usuário indagou se a água parada no açude não teria sua qualidade afetada. O membro da comissão gestora do açude informou que houve grande liberação de água (a água, portanto, não estaria parada) e que houve perdas, pois o leito do riacho se encontrava bastante assoreado, causando transbordamentos e impedindo as águas de chegarem às comunidades a jusante. A Cogerh solicitou aos usuários que avisassem de perdas e fugas para proporcionar uma solução rápida. Um usuário falou da importância de participação da sociedade e referiu-se ao fato de que, em 2004, havia muitos barramentos no leito do riacho e, com a conscientização popular, não havia mais nenhum em 2007. Esse fato foi considerado um ganho do processo participativo.

Um usuário pediu informações sobre o início do período da operação, pois, em sua comunidade, já estava faltando água, ressaltando que, no ano 
anterior (2006), havia ficado sem água durante quatro meses. A Cogerh informou que já tinha sido decidido o valor da vazão a ser liberada e lembrou que o comitê deliberou que a vazão do Manoel Balbino ficaria entre 45 l/s e 65 l/s. Ao cabo dos debates, ficou acordado entre os presentes que a vazão liberada do açude Manoel Balbino seria de $45 \mathrm{l} / \mathrm{s}$ até o mês de dezembro.

Dando prosseguimento à reunião, iniciou-se a análise de vazão do açude Thomas Osterne. O técnico da Companhia de Águas e Esgotos (Cagece) solicitou informações a respeito da vazão desse açude. Foi explicado pelo técnico da Cogerh que a proposta de vazão se encontrava dentro da média operada. Um usuário lamentou por não chegar água à sua comunidade, frisando que se ele não tinha água, os outros também não deveriam ter. Outro usuário pediu providências, uma vez que se encontrava sem água havia uma semana, e que no ano anterior teria passado o segundo semestre nesta situação. Novamente o secretário-geral do comitê informou que quem tivesse algo a reclamar teria que procurar a Cogerh bem como o Comitê da Bacia.

Um usuário requereu que o Comitê da Bacia se reunisse no município do açude e não em outros municípios. A Cogerh acentuou que a cidade de Brejo Santo faz parte da bacia e que o comitê poderia fazer reuniões em qualquer dos seus 23 municípios. O secretário-geral pediu a palavra e explicou que os usuários devem informar ao comitê tudo o que acontecesse na bacia para que o colegiado pudesse tomar as providências necessárias. Ele ressaltou que o comitê se preocupava com toda a sociedade, tanto usuários de grande como de pequeno porte, sem desmerecer ninguém; e disse que a gestão das águas é um dos pontos mais democráticos do Ceará. Após as simulações, a comissão deliberou que a vazão liberada do açude Thomas Osterne seria de 250 l/s até o mês de setembro, e 300 l/s até o mês de dezembro.

A Cogerh, em maio de 2006, informou que existiam cadastrados aproximadamente 80 usuários no vale dos Carás, a jusante do açude Thomas Osterne, tanto na margem direita como na esquerda, irrigando pelos métodos inundação e/ou aspersão, cultivando várias culturas, tais como: banana, capim de corte, capim-elefante, milho, feijão, pimenta, arroz, cheiro-verde, tomate e outras; e que haveria necessidade de fazer um novo levantamento cadastral, principalmente coletando dados quanto ao consumo de água.

A SRH/CE informou, em junho de 2007, que em seu banco de dados de outorga, a partir de 1998, havia 44 solicitações de outorga, mas que naquela data apenas três delas estavam em vigor. 


\subsection{A análise do conflito}

Podem-se observar, pela análise histórica do conflito, alguns pontos importantes:

1. embora estabelecida por lei desde 1992, a organização do sistema de outorgas não havia sido convenientemente efetivada até o ano de 2007. Observou-se que das 44 solicitações de outorga, haviam sido arquivadas 41 e somente três estavam vigentes em 2007;

2. as águas do vale são de domínio da União e do estado, o que implicou a participação de duas instituições gestoras - o Dnocs na esfera federal e a Cogerh na estadual.

3. a constatação do caráter político da gestão de águas pode ser inferida pelas instituições participantes no processo de exacerbação ou mediação do conflito. Participaram os usuários, como partes interessadas; o Ministério Público, feito defensor dos interesses difusos da sociedade; a Câmara de Vereadores, na qualidade de representantes políticos dos munícipes envolvidos no litígio; o sindicato; e a Justiça;

4. Há necessidade de vigilância constante por parte da sociedade, visto que os processos de retenção de águas por usuários de montante se mostram recorrentes quando das crises de água;

5. os acordos nas alocações negociadas mostraram-se um excelente avanço na forma de negociação, pois estabeleceram acordos e propiciaram muitas ações pacíficas, como a destruição de barragens de terra e a abertura de comportas para liberação de águas para jusante.

6. mesmo com os acordos e os avanços, alguns usuários demonstram-se não participativos, obrigando a recorrer-se a ações da Justiça, o que exibe claramente a complexidade do sistema da gestão de águas.

\section{Conclusões}

O monitoramento ao longo do riacho perenizado torna-se uma ferramenta de suma importância para se manter a perenização em equilíbrio, não trazendo desabastecimento das demandas nem desperdícios de água. O monitoramento deve ser visto como um processo essencial à implantação dos instrumentos da gestão dos recursos hídricos, permitindo a obtenção de informações estra- 
tégicas, o acompanhamento das medidas efetivas, a atualização dos bancos de dados e o direcionamento das decisões. O conhecimento da realidade é fundamental para a identificação dos interesses de uso em relação a um determinado corpo d'água. O envolvimento dos usuários no processo de alocação participativa da água é um elemento relativamente novo. Portanto, é fundamental garantir a representação de todos os interesses de uso durante todo o processo.

No Ceará, a alocação negociada de água ocorre anualmente, após a quadra chuvosa, por meio de seminários sobre a situação atual, fazendo-se a simulação de esvaziamento dos açudes, a avaliação da demanda, a definição da vazão a ser liberada e a formação de uma comissão de usuários, com o devido registro em atas assinadas por seus participantes.

O presente trabalho enfocou o conflito estabelecido no vale dos açudes Thomas Osterne e Manoel Balbino em anos de escassez — o de maior número de construção de obras hidráulicas ao longo do riacho e que envolve grandes áreas inundadas com plantio de várias culturas.

O modelo de negociação praticado mostrou muitos ganhos no aspecto participativo. Observe-se que a destruição de barragens de terra foi conseguida após muita negociação e, principalmente, sem conflitos armados, como ocorria no passado em disputas relativas ao uso da água.

A gestão de águas é um conjunto de atos políticos e participativos em essência. O estudo de caso analisado mostra o surgimento de outra cultura de negociação, envolvendo vários segmentos da sociedade. Substancialmente, a prática da gestão de águas na busca de soluções de conflitos resulta em um processo de crescimento da sociedade.

\section{Referências}

CAMPOS, J.N.B.; STUDART, T.M.C. Gestão de águas: princípios e práticas. Porto Alegre: ABRH, 2001.

CAMPOS, J.N.B.; STUDART, T.M.C.; COSTA, A.M. Alocação e realocação do direito de uso da água: uma proposta de modelo limitado no espaço. Revista Brasileira de Recursos Hídricos, Porto Alegre, v. 7., n. 2, 2002.

CARVALHO, R.C. Gestão dos recursos hídricos: conflito e negociação na questão das águas transpostas da bacia do Paraíba do Sul. Tese (doutorado) - Coppe, Universidade Federal do Rio de Janeiro, Rio de Janeiro, 2005. 
CEARÁ. Governo do estado. Plano estadual dos recursos hídricos. Fortaleza: Secretaria dos Recursos Hídricos, 1992.

COGERH. Alocação negociada de água da bacia do Salgado: relatório interno da Gerência da Bacia do Salgado. Crato-CE: COGERH/SRH, 2000.

COGERH. Alocação negociada de água dos açudes Thomas Osterne e Manoel Balbino: Relatório alocação. Crato: Cogerh/SRH, 2007.

CORREIA, C.A. A construção de cenários hidrológicos como ferramenta para solução de conflitos: o caso da bacia do rio Poti. Dissertação (mestrado) — Universidade Federal do Ceará, Ceará, 2006.

GLEICK, P.H. Water conflict chronology. Studies in development, environment and security. The Pacific Institute, 2000. Disponível em: <www.worldwater.org/conflict.htm $>$.

KEMPER, K.E. O custo da água gratuita: alocação e uso dos recursos hídricos no vale do Curu, Ceará, Nordeste brasileiro (The cost of free water: water resours allocation and use in the Curu valley, Ceará, Northeast Brazil. Linkoping). Porto Alegre: ABRH, 1996.

PINHEIRO, M.I.T. Tipologia de conflitos de usos das águas: estudos de casos no estado do Ceará. Dissertação (mestrado) — Universidade Federal do Ceará, Fortaleza, 2002. 